https://helda.helsinki.fi

\title{
Phosphorylation of MAP Kinases crucially controls the response to environmental stress in Dunaliella viridis
}

\section{Ortiz Charneco, Guillermo}

\author{
2018-12
}

Ortiz Charneco , G , Parages , M L , Camarena-Gómez , M T \& Jimenez , C 2018 , '

Phosphorylation of MAP Kinases crucially controls the response to environmental stress in

Dunaliella viridis ' , Environmental and Experimental Botany , vol. 156 , pp. 203-213 . https://doi.org/10.1016/j.envex

http://hdl.handle.net/10138/319484

https://doi.org/10.1016/j.envexpbot.2018.08.030

cc_by_nc_nd

acceptedVersion

Downloaded from Helda, University of Helsinki institutional repository.

This is an electronic reprint of the original article.

This reprint may differ from the original in pagination and typographic detail.

Please cite the original version. 
$4 \quad$ Phosphorylation of MAP Kinases crucially controls the response to environmental stress in Dunaliella viridis

8 Guillermo Ortiz Charneco ${ }^{*}, 1,2$, María L. Parages ${ }^{*}, 1,{ }^{* *}$, M. Teresa Camarena-Gómez ${ }^{3}$ \& 9 Carlos Jiménez ${ }^{1}$

$10 *$ Both authors contributed equally to this publication

$11 * *$ Author for correspondence. Email: malopa@uma.es

12 1-Department of Ecology, Faculty of Sciences, University of Málaga, 29071 Málaga, 13 Spain

14 2- Present address: Alimentary Pharmabiotic Centre, University College Cork, Cork, 15 Ireland

16 3- Tvärminne Zoological Station, University of Helsinki, J.A. Palménin tie 260, 10900

17 Hanko, Finland

18

19

20 
The green unicellular microalga Dunaliella viridis has the ability to cope with a wide variety of environmental stressful conditions, such as thermal and osmotic shocks, high PAR, UV radiation and nitrogen deficiency. The lack of a rigid cell wall makes $D$. viridis an excellent model organism to study stress signaling in eukaryotic unicellular organisms. Mitogen-activated protein kinases (MAPKs) are highly conserved serine/threonine kinases that convert extracellular stimuli into a wide range of responses at both cellular and nuclear levels. In eukaryotic cells, MAPKs are involved in both cell proliferation and differentiation (ERK pathway) and stress responses (JNK and p38 pathways), through protein kinase cascades. Significantly lesser phosphorylation levels of ERK-like protein were observed in D. viridis cultures acclimated to high salinity (3$4 \mathrm{M} \mathrm{NaCl}$ ). In contrast, JNK-like and p38-like proteins phosphorylation levels increased in stressed cells. Likewise, the efficacy of specific commercial inhibitors of the phosphorylation of ERK (PD98059), JNK (SP600125) and p38 (SB203580) revealed the importance of JNK-like proteins in the maintenance of cell viability, the highlighted participation of p38-like proteins and the non-direct implication of the ERK-like proteins in the acclimatization process. In summary, specific blockade of JNK- and p38like cascades in stressed cells led to rapid cell death. The behavior of MAPK-like proteins in algae is not known in depth, so the analysis of their mechanism of action, as well as their function in this model microalga, will allow to estimate the fate of unicellular eukaryotic organisms in aquatic ecosystems subjected to environmental stress derived from the conditions prevailing within a framework of global climate change.

Keywords: Dunaliella, MAP Kinases, Environmental stress, Hypersalinity, UV 


\section{Introduction}

All organisms have to acclimate to their environment in order to survive. The response to a changing environment requires that organisms must be able to perceive the stimuli and external cellular signals and, consequently, to develop appropriate cellular responses that enable them to survive against environmental changes. Microalgae, as well as vascular plants, are permanently exposed to changes in environmental conditions. To survive, they have developed a complex network of biochemical signals that allow them to perceive environmental changes and respond to them. This process usually leads to a response within the cell that allows it either to acclimate to the new conditions of the environment or to start a process that will cause cell death. In general, external information is transmitted to the cell nucleus through a series of phosphorylation and de-phosphorylation reactions of certain proteins (kinases), which induce the activation or deactivation of specific genes (Kyriakis \& Avruch, 2001).

Increasing evidences show that mitogen-activated protein kinases (MAPKs) occupy the central core of the network of phosphorylations and de-phosphorylations that takes place when plants have to deal with a situation of stress. MAPKs are a group of highly conserved serine/threonine kinases, ubiquitous in all eukaryotic cells. They have been widely studied in organisms from yeast to humans as transducers of extracellular signals into a variety of cytoplasmic and nuclear responses (Widman et al., 1999). The MAPKs, together with their activators (the so-called MAPK kinases - MAPKK and MAPK kinases kinases - MAPKKK) form a cascade.

To date, six MAPKs cascades have been identified in mammalian cells, but only for some of them have all the components been completely identified: extracellular signalregulated kinase (ERK), stress-activated protein kinase/c-Jun N-terminal kinase (SAPK/JNK) and p38. When phosphorylated, both p38 and JNK trigger the response to stress, while ERK controls cell proliferation and differentiation (Ligterink, 2000). The presence of MAPK-like pathway components in algae has been described previously by our group (Jiménez et al., 2004, 2007). We reported the presence of both JNK- and p38like MAPKs in the unicellular chlorophyte Dunaliella viridis and their involvement in survival of cells under stress, also showing the presence of ERK1/2 in this microalga and its participation in cell division. In addition, the phosphorylation of MAPK-like proteins in response to environmental stress has been shown in macroalgae by Parages 
et al., 2012, 2013, 2014. These results, together with others (García-Gómez et al., 2012; Gasulla et al., 2016), indicate that algae possess MAPK-like signaling components that are essential to sense and respond to different stress, allowing cell acclimation and survival.

Exposure to low levels of stress usually generates an acclimatization process in the organisms, resulting in a transient resistance at higher levels of the same stress. This acclimatization to stress can also induce a greater tolerance (cross-protection) to other stresses (Chen et al., 2003, Lurie et al., 1994), which is usually short, requiring de novo protein synthesis. Thus, the phenomenon of cross-protection suggests a general response mechanism to stress that may confer a basic level of protection against the action of any factor responsible for the stress. Responses against different environmental stress situations must be given to maintain cell survival and proliferation, and so the characterization of these responses, the mechanisms involved in the detection of stress, the transmitting signals of this information to the cell and the nucleus, and compensatory changes resulting in physiology and gene expression, are essential to understand how cells respond and survive under non-ideal conditions (Chen et al., 2003).

The present study was performed in a model microalga of the genus Dunaliella, that thrives in hypersaline aquatic environments and which needs to cope with rapid changes in salinity, radiation and temperature, among other stresses. Halotolerant algae of the genus Dunaliella are the most ubiquitous eukaryotic microorganisms in hypersaline environments, and can survive even in saturated salt solutions $(\approx 5.5 \mathrm{M} \mathrm{NaCl})$ (BenAmotz \& Avron, 1983, 1990). These organisms have to face sudden changes in salinity, irradiance and nutrient availability that usually occur in their natural habitat. The lack of a rigid cell wall permits rapid changes in cell shape and volume in response to osmotic shocks. After a change in the external salinity, Dunaliella osmoregulates by varying the intracellular concentration of glycerol (Ben-Amotz \& Avron, 1973). Transition to the new osmotic conditions lasts $1-3 \mathrm{~h}$, and during most of this period cell division does not occur (Avron, 1992).

The experiments were designed to explore the possibility that these lower organism respond to sudden changes of the environmental conditions (hypersalinity, high irradiance and UV radiation, all stressful but non-lethal exposures) by activating MAP kinase signaling pathways such as p38 and JNK, while deactivation of ERK would 
reduce cell proliferation. Inhibiting these pathways would compromise the ability of this microalga to acclimate to the new prevailing conditions, thus leading to cell death.

\section{Material and methods}

Microalgae culture

D. viridis Teodoresco was isolated from the athalassic lake of Fuente de Piedra (Málaga, Spain) and grown in batch culture as previously described (Jiménez et al., 2007), in a basal medium that contained $1 \mathrm{M} \mathrm{NaCl}, 5 \mathrm{mM} \mathrm{KNO}_{3}, 0.25 \mathrm{mM} \mathrm{KH}_{2} \mathrm{PO}_{4}, 50$ $\mathrm{mM} \mathrm{NaHCO}{ }_{3}^{-}$. Cells were cultivated under continuous orbital shaking and illumination $\left(30 \mu \mathrm{mol} \mathrm{m} \mathrm{s}^{-1}\right)$, being this illumination provided by commercial cool white fluorescent lamps, at a temperature of $25^{\circ} \mathrm{C}$. Cell density was determined by means of counting viable cells using a hemocytometer and a flow cytometer (BD Biosciences, BD Accuri C6 Flow Cytometer, San José, CA, USA).

\section{Experimental conditions}

The ability of $D$. viridis to survive at increasing salinities was estimated by growing the cells at 1,2, 3 and $4 \mathrm{M} \mathrm{NaCl}$ for a period of several weeks. The time that each culture took to reach the desired cell density, depending on the salinity in the medium, can be observed in Figure 1.

For short-time experiments, cells in their mid-exponential phase of growth, at a

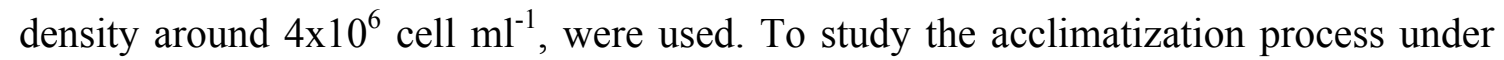
different stress situations, cells were exposed to three types of stress, including: (i) hyperosmotic stress, (ii) high irradiance, and (iii) UV radiation. All the three stressful conditions described below are non-lethal for $D$. viridis under the detailed conditions. Hyperosmotic stress consisted in a sudden increase of the osmotic pressure in the medium by the addition of $\mathrm{NaCl}$, from an initial concentration of $1 \mathrm{M} \mathrm{NaCl}$ to a final of 2.5 $\mathrm{M} \mathrm{NaCl}$. For high irradiance stress, cultures were exposed to an incident irradiance of $3000 \mu \mathrm{mol} \mathrm{m} \mathrm{m}^{-2}$ of white light for 35 minutes, using a LED Explosion proof lamp $(120 \mathrm{~W})$, and were then kept under the same conditions as described above $\left(30 \mu \mathrm{mol} \mathrm{m}{ }^{-}\right.$ ${ }^{2} \mathrm{~s}^{-1}$ under orbital shaking). The emission spectrum of the lamp is shown in Figure 2a. After exposure, cells were kept under continuous orbital shaking at an irradiance of 30 $\mu \mathrm{mol} \mathrm{m} \mathrm{s}^{-2}$ of PAR. Samples were withdrawn at the described times in the figures. The 
influence of UV radiation was studied through the exposure of the cultures of $D$. viridis to a total dose of $480 \mathrm{~mJ} \mathrm{~cm}^{-2}\left(20 \mathrm{~W} \mathrm{~m}^{-2}\right)$ of UV light in the range $200-400 \mathrm{~nm}$, using two UV lamps (Philips TL 36W/12, Philips Co. Holland, Philips Co. Holland) as previously reported (Jiménez et al., 2004). Spectral irradiance of the UV lamps is shown in Figure 2b. $50 \mathrm{ml}$ of $1 \mathrm{M} \mathrm{NaCl}$ cultures were placed in Petri dishes of $14 \mathrm{~cm}$ in diameter (in triplicate), and after UV exposure they were kept under continuous orbital shaking at an irradiance of $30 \mu \mathrm{mol} \mathrm{m} \mathrm{s}^{-2}$ of PAR during the next $24 \mathrm{~h}$ for recovery. Samples were withdrawn at the described times in the figures.

\section{Treatment with inhibitors}

Before exposure to stress, aliquots of the microalgae culture were transferred to 50 $\mathrm{ml}$ conical tubes (in triplicate). Appropriate volumes of very specific inhibitor solutions in dimethilsulphoxide (DMSO) (1000× stock) were added to make the culture medium $1 \mu \mathrm{M}$ in SP600125 (JNK inhibitor), $20 \mu \mathrm{M}$ in PD98059 (ERK inhibitor) (Calbiochem, La Jolla, CA, USA) or $20 \mu \mathrm{M}$ in SB203580 (p38 inhibitor) (Caymanchem, Ann Arbor, MI, USA). At these concentrations, these molecules have been largely proved to be very selective inhibitors of the JNK (Bennet et al., 2001), ERK (Jiménez et al., 2007) and p38 (Capasso et al., 2001) pathways, respectively, being selective and cell wall permeable that act by inhibiting the phosphorylation of the MAPKs and the subsequent phosphorylation of downstream substrates. No significant inhibition of phosphorylation of other MAPKs is expected. After $2 \mathrm{~h}$ of incubation in darkness with the inhibitor, cells were exposed to the different environmental stress conditions as described above.

\section{Western blot analysis}

At fixed times, an aliquot of culture was removed and centrifuged at $1500 \mathrm{xg}$ for 10 min. Pellets were then resuspended in $1 \mathrm{ml}$ of MAPK lysis buffer (Capasso et al., 2001) and placed in ice for $1 \mathrm{~h}$, with vortexing every $10 \mathrm{~min}$. Samples were frozen in liquid $\mathrm{N}_{2}$ and kept at $-80^{\circ} \mathrm{C}$ or processed immediately. After thawing, samples were centrifuged at $15,000 \mathrm{~g}$ for $60 \mathrm{~min}$ in an Eppendorf ${ }^{\circledR}$ Centrifuge 5804/5804R. Supernatants were frozen at $-80^{\circ} \mathrm{C}$ until further analysis. Protein concentration of each supernatant was determined by the bicinchoninic acid method (Pierce, Rockford, IL, USA). Equal amounts of protein were loaded per lane (40 $\mu \mathrm{g} / \mathrm{lane}$ ) for SDS-PAGE. A certain number 
180

181

182

183

184

185

186

187

188

189

190

191

192

193

194

195

196

197

198

199

200

201

202

203

204

205

206

207

208

209

210

211

212

of samples were run in duplicate gels, with one of them stained with Coomassie Blue to confirm uniform protein loading, and the second one used for MAPK immunodetection. SDS-PAGE, electroblot to poly(vinylidene difluoride) membrane (Amersham HybondP PVDF membrane; GE Healthcare, Buckinghamshire, UK), and immunodetection were performed as previously described (Capasso et al., 2001; Jiménez et al., 2004). Immunodetection was carried out using antibodies against the phosphorylated forms of mammalian p38, ERK and JNK proteins (Ph-p38 \#9211, Ph-JNK \#9251, Ph-p44/p42 \#9106; Cell Signaling Technology, Beverly, MA, USA). Phospho-p44/p42 MAP kinase (Thr202/Tyr204) antibody detects endogenous levels of p44 and p42 MAP kinase (ERK1 and ERK2), but only when catalytically activated by phosphorylation at Thr202 and Tyr204 of human ERK, or Thr183 and Tyr185 of rat ERK2. This antibody does not cross-react with the corresponding phosphorylated residues of either JNK/SAPK or p38 MAPK. The phospho-p38 antibody detects only the phosphorylated form of this kinase and is specific for the antigen sequence $\mathrm{T}^{*} \mathrm{GY}^{*}$, not showing cross-reaction with similar sequences such as TPY (JNK) or TEY (ERK). This phospho-p38 does not react with either the non-phosphorylated or single phosphorylated form of the protein. The phospho-JNK antibody used is specific for the T*PY* sequence and only when doublephosphorylated, not recognizing either the non-phosphorylated or single phosphorylated form of this protein and not cross-reacting with p38 or ERK. This antibody recognizes all isoforms of the JNK protein. Secondary antibody used against the primary antibodies was Anti-rabbit IgG, HRP linked (\#7074, Cell Signaling Technology, Beverly, MA, USA). The antibody concentration was $1 / 1000$ (primary antibody) and 1/2000 (secondary antibody), diluted in $10 \mathrm{ml}$ of bovine serum albumin (BSA) with 3\% TTBS. Membranes were analysed using a Kodak Gel Logic 1500 Image System, using Amersham ECL Advance (GE Healthcare, Buckinghamshire, UK) as a chemiluminiscence agent following the recommended conditions by the manufacturer. Further band intensity analysis was performed using the ImageJ 1.440 free software (National Institute of Health, USA).

\section{PAM fluorometry}

The physiological fitness of $D$. viridis was followed by measuring the photosynthetic efficiency using PAM-fluorometry, with a WATER-PAM (Heinz Walz GmbH, Effeltrich, Germany). Maximum quantum yield of Photosystem II (PSII) fluorescence 
$213\left(F_{\mathrm{v}} / F_{\mathrm{m}}\right)$ was measured in parallel with sampling for the subsequent Western Blot 214 analysis, with the WinControl-3 software, as previously described (Schreiber et al., 215 1986). $F_{\mathrm{v}} / F_{\mathrm{m}}$ was considered as $\left(F_{\mathrm{m}}-F_{\mathrm{o}}\right) / F_{\mathrm{m}}$, where $F_{\mathrm{v}}$ is the maximal variable

216 fluorescence of a dark-adapted sample, $F_{\mathrm{m}}$ is the maximal fluorescence intensity with 217 all PSII reaction centers closed, and $F_{0}$ is the basal fluorescence, thus obtaining the 218 parameter $F_{\mathrm{v}} / F_{\mathrm{m}}$, which represents the maximum quantum yield of the photosystem II 219 when all reaction centers are open after a period of darkness adaptation (Baker and 220 Oxborough, 2004). High $F_{\mathrm{v}} / F_{\mathrm{m}}$ values indicate the good condition of the cells, whereas 221 low values indicate stress and photoinhibition.

Maximum relative electron transport rate $\left(\mathrm{rETR}_{\max }\right.$, measured in $\mu \mathrm{mol}$ electrons $\mathrm{m}^{-2} \mathrm{~s}^{-}$ ${ }^{1}$ ) through PSII was directly given by the Water PAM, and no transformation was carried out.

\section{Statistical data analysis}

All experiments were run in triplicate. Data presented here are means $\pm \mathrm{SD}$. Results were analysed by using the SigmaPlot 11.0 statistical package (SPSS). A value of $p<$ 0.05 was considered significant and is represented in the graphs with a single asterisk “*”, while a value of $\mathrm{p} \leq 0.001$ was considered very significant and is represented by two asterisks “**”.

\section{Results}

\section{Long-term acclimation to hypersaline conditions}

Before performing the above-detailed experiments for the identification of the role of the three MAPKs in the response to acute stress, photosynthetic performance of $D$. viridis long-term acclimatized to four increasing salinities $(1,2,3$ and $4 \mathrm{M} \mathrm{NaCl})$ was assessed by determination of $\mathrm{F}_{\mathrm{v}} / \mathrm{F}_{\mathrm{m}}$, and the level of phosphorylation of the three MAPK-like proteins was studied. As already mentioned in Material and Methods, $D$. viridis was cultured for several weeks at 1,2, 3 and $4 \mathrm{M} \mathrm{NaCl}$, and a significant decrease of $\mathrm{F}_{\mathrm{v}} / \mathrm{F}_{\mathrm{m}}$ values at high salinity was detected; the lowest performance was found at 3 and $4 \mathrm{M}$, increasing at 1 and $2 \mathrm{M} \mathrm{NaCl}$. In addition, no significant differences were

243 found between the cultures subjected to 1 and $2 \mathrm{M} \mathrm{NaCl}$ (Fig. 3a). Even though $\mathrm{F}_{\mathrm{v}} / \mathrm{F}_{\mathrm{m}}$ 
was significantly lower at the highest salinity, absolute values of this photosynthetic parameter at $4 \mathrm{M} \mathrm{NaCl}(>0.55)$ support the very well known capacity of $D$. viridis to thrive at salinities near saturation. This conclusion was supported also by the high values of the maximum relative electron transport rate $\left(\mathrm{rETR}_{\max }\right)$ found in all conditions (Fig. 3b). These results indicate that even at salinity as high as $234 \mathrm{~g} \mathrm{NaCl} / 1$ D. viridis maintains a high capacity to develop a very efficient photosynthesis. Since $F_{v} / F_{m}$ values provided detailed information on the physiological state of the microalga, this parameter was chosen preferably during the rest of the work to estimate its physiological condition when exposed to sudden stresses both in the presence and absence of specific inhibitors of the MAPKs.

MAPKs phosphorylation was also studied in cultures that were long-term 255 acclimatized to the salinity range $1-4 \mathrm{M} \mathrm{NaCl}$ (Fig. 4). No significant differences were found in the phosphorylation levels of either JNK-like or p38-like proteins in cultures exposed to increasing salinities. A basal and similar level of phosphorylation of both MAPKs was always detected in these long-term acclimated conditions, independently of the salinity in which cells were cultured. However, a significant difference in the intensity level of phosphorylation of ERK-like proteins could be observed. The level of phosphorylation of ERK was significantly lower at the highest salinities $(p \leq 0.001)$, which is consistent with previously reported data of growth rate of $D$. viridis under different salinities.

\section{MAPK-like phosphorylation after hypersaline stress}

The role played by the three MAPKs (ERK, JNK and p38) in D. viridis cultures exposed to different environmental stress situations has been assessed using very specific commercial inhibitors of each protein, largely proved to specifically block phosphorylation of the detailed MAPK. Thus, the comparison between the experiments performed either in the presence or the absence of inhibitors, permits to estimate the different role played by these MAPKs in the maintenance of cell viability after an environmental stress situation.

The response of $D$. viridis photosynthetic performance after hypersaline stress 274 (mediated by the non-lethal addition of $\mathrm{NaCl}$ from $1 \mathrm{M}$ to 2.5) is shown in Figure 5. As 275 it can be seen, the mean $\mathrm{F}_{\mathrm{v}} / \mathrm{F}_{\mathrm{m}}$ value obtained in basal conditions, without stress or inhibitor (control treatment), was 0.687. This value decreased when the cultures 
277 underwent osmotic shock, reaching its lowest value at $\mathrm{t}=4 \mathrm{~h}\left(\mathrm{~F}_{\mathrm{v}} / \mathrm{F}_{\mathrm{m}}=0.509\right)$. From that 278 minimum, $\mathrm{F}_{\mathrm{v}} / \mathrm{F}_{\mathrm{m}}$ steadily recovered during the next hours attaining values at $24 \mathrm{~h}$ similar to those expected at the new osmotic pressure. However, in the presence of the specific inhibitors of the MAPKs cascades, differential responses of $F_{v} / F_{m}$ were found. The inhibition of the ERK cascade (see Materials and Methods for details) followed by the addition of $\mathrm{NaCl}$ to make $2.5 \mathrm{M} \mathrm{NaCl}$ did not have any effect on the photosynthetic performance of $D$. viridis, remaining $\mathrm{F}_{\mathrm{v}} / \mathrm{F}_{\mathrm{m}}$ values very similar to those from the control. These results suggest that ERK-like proteins are not involved in the response to stress. When the cascade of p38-like proteins was inhibited, significant differences could be found when compared to the control. In the first 4 hours after subjecting $D$. viridis to hyperosmotic stress in the presence of the p38 cascade inhibitor, the drop of $\mathrm{F}_{\mathrm{v}} / \mathrm{F}_{\mathrm{m}}$ was not significantly different when compared to the control $(\mathrm{p}=0.073)$. However, after this time differences with the control were observed, and $F_{v} / F_{m}$ never recovered to values similar to control ( $\mathrm{p} \leq 0.001$ at $24 \mathrm{~h}$ ). D. viridis seemed to be unable in the mid term to fully recover its cell performance when p38 was inhibited.

In addition, pre-incubation with the JNK cascade inhibitor produced the most drastic effect. When exposed to hyperosmotic stress (after incubation with the JNK inhibitor) $\mathrm{F}_{\mathrm{v}} / \mathrm{F}_{\mathrm{m}}$ values dropped rapidly, from 0.687 to 0.189 within 30 minutes. One hour after stress, $\mathrm{F}_{\mathrm{v}} / \mathrm{F}_{\mathrm{m}}$ values were around 0.08 , dropping to 0 in the successive hours. Microscopic analysis of the cells (not shown) indicated that $100 \%$ of the cells were dead since the cell membrane was broken. These results show the crucial dependence of response to hyperosmotic stress in $D$. viridis and phosphorylation of the JNK.

Additionally, the phosphorylation level of the three MAPKs was studied by means of immunodetection. Figure 6 shows the time-course of the phosphorylated forms of ERK, p38 and JNK when the cultures of $D$. viridis were exposed to hypersalinity both in the presence and absence of their specific inhibitors. A band of $42 \mathrm{kDa}$ of estimated molecular weight was identified by the specific antibody against the phosphorylated form of the ERK (Fig. 6a), while the specific antibody against the JNK/SAPK crossreacted with a $45 \mathrm{kDa}$ protein (Fig. 6b). Finally, a phosphorylated protein of $57 \mathrm{kDa}$ was detected by the antibody against the phospho-p38-MAPK (Fig. 6c).

Two noticeable facts seem to occur after the increase of the salinity: first, while the phosphorylation level of both p38 and JNK immediately increased after the onset of the stress, phosphorylation of the ERK rapidly decreased; second, the phosphorylation of 
all three MAPKs decreased in the presence of the inhibitor. In the case of ERK, the extent of the decrease was more pronounced than in control cells (absence of inhibitor). In all cases, the phosphorylation of the MAPKs remained lowest in the presence of the inhibitor $24 \mathrm{~h}$ after the increase of the salinity.

In the controls, an increase on the phosphorylation levels of JNK-like proteins could be seen in the short and medium term after hyperosmotic stress, whereas in the presence of the specific JNK cascade inhibitor, this MAPK was progressively dephosphorylated. An initial presence of phosphorylated JNK-like proteins, even after being incubated with the inhibitor, seems to correspond to an existing basal reserve of JNK, despite the arrest on the phosphorylation of these proteins.

There was also a phosphorylation of p38-like proteins after hyperosmotic shock in control cells, experiencing a slight dephosphorylation within 2 hours after the shock, but maintaining high phosphorylation levels in the medium term. On the other hand, by inhibiting the p38 cascade, this protein remained dephosphorylated, presenting the aforementioned effects on cell viability.

ERK phosphorylation, as expected, highly decreased after the shock, indicating a sudden arrest of cell division. In addition, de-phosphorylation of this MAPK-like protein was more pronounced after stress in the presence of the inhibitor.

\section{MAPK-like phosphorylation after high irradiance stress}

The effect of high irradiance was studied exposing D. viridis cultures to $3000 \mu \mathrm{mol}$ $\mathrm{m}^{-2} \mathrm{~s}^{-1}$ of PAR for 35 minutes. By using MAPKs specific inhibitors, as in the previous case, it was possible to estimate the different role played by these three MAPKs in maintaining cell viability after an environmental stress situation such as a high irradiance event.

After the shock, an immediate drop of $\mathrm{F}_{\mathrm{v}} / \mathrm{F}_{\mathrm{m}}$ occurred in control cells to figures around 0.38 , which steadily increased to initial values during the next $24 \mathrm{~h}$ (Fig. 7). A similar response was found in the cultures incubated with the ERK inhibitor before the stress. In contrast, cells treated with either the p38 or the JNK inhibitor before the stress, showed a clear decrease of photosynthetic efficiency $(\mathrm{p} \leq 0.001)$ after the transient exposure to high irradiance. The loss of efficiency was much more drastic and lasting in the presence of the JNK inhibitor. In this case, $F_{v} / F_{m}$ values $24 \mathrm{~h}$ after exposure to high 
342 irradiance were below 0.1 , indicating that $D$. viridis was not capable of recovering (not

343 being able to trigger its acclimatization responses) after the high irradiance shock.

344 Protein analysis by means of immunodetection revealed that phosphorylation of the $42 \mathrm{kDa}$ band (ERK-like MAPK) was immediately reduced after the stress, and that the extent of this inhibition was much more patent in the presence of the ERK specific inhibitor (Fig. 8a), like in the previous experiment. The response of JNK was, as expected, somehow different. In the control, an initial and fast phosphorylation of JNKlike proteins occurred, remaining at high levels $24 \mathrm{~h}$ after the shock, while when inhibiting this MAPK, its phosphorylation levels were significantly lower. Under this stress, two JNK-like proteins of 45 and $43 \mathrm{kDa}$ were identified (Fig. 8b). Finally, p38like proteins showed a similar behavior to that presented in the hyperosmotic shock. A rapid phosphorylation of p38-like proteins occurred in the control, which remained $24 \mathrm{~h}$ after stress (Fig. 8c). In the presence of the inhibitor of p38 phosphorylation, no response to high irradiance stress was detected, and a fast de-phosphorylation of the 57 $\mathrm{kDa}$ phosphoprotein occurred in the first minutes.

\section{MAPK-like phosphorylation after UV radiation stress}

D. viridis response to stress induced by non-lethal doses of UV radiation was estimated by exposing the cultures to $480 \mathrm{~mJ} \mathrm{~cm}^{-2}\left(20 \mathrm{~W} \mathrm{~m}^{-2}\right)$ of UV in the range 200$400 \mathrm{~nm}$. Photosynthetic efficiency of this microalga dropped to values around $0.57 \mathrm{a}$ few minutes after exposure, both in control cultures and in the presence of ERK inhibitor (Fig. 9). However, inhibition of either p38 or JNK caused a very significant decrease of $\mathrm{F}_{\mathrm{v}} / \mathrm{F}_{\mathrm{m}}$ values (in accordance with their roles in environmental stress acclimation), being this decrease far more drastic when inhibiting JNK (0.42 in the presence of $\mathrm{p} 38$ inhibitor and 0.15 in the presence of the JNK one).

When exposed to a non-lethal UVR dose, phosphorylation of ERK-like proteins did not show significant differences along the experiment (Fig. 10a). However, incubating the cultures with the ERK inhibitor produced a very significant decrease of the phosphorylation of this MAPK-like protein. In the case of the JNK, treatment with nonlethal UVR caused its immediate phosphorylation, which levels increased during the following $24 \mathrm{~h}$ after stress (Fig. 10b). By employing the inhibitor of the JNK, phosphorylation of this MAPK was prevented, and only residual phosphorylation 
374 remained after $24 \mathrm{~h}$. Finally, the p38-like MAPK (57 kDa) did not show significant 375 changes along time when exposed to the above-mentioned levels of UVR (Fig. 10c). 376 Furthermore, when incubating with the p38 inhibitor, the phosphorylation level of p38377 like MAPK decreased significantly, reaching its lowest level after 30 minutes, and 378 remaining low for the rest of the experiments.

\section{Discussion}

381 Animals have several well-characterized MAPK cascades that participate in cellular 382 responses to a wide variety of stress and in the control of cell division and 383 differentiation. These cascades consist of a series of protein kinases that are phosphorylated and activated in a sequential way, associated with the downstream protein kinase. Both the p38 and the JNK cascades are responsible for stress adaptation, whereas the ERK cascade is involved in mitogenic stimuli and differentiation (Widmann et al., 1999). MAPKs may also be involved in the signal transduction of several environmental factors in plants (Hirt, 1997; Tena \& Renaudin, 1998; Sinha et al 2011; Danquah et al., 2014; Yanagawa et al., 2016). These proteins participate in the response to a broad range of extracellular stimuli, such as growth factors, drought, UV radiation, osmotic changes, temperature stress, etc., and are involved in the operation of several cell programs, such as cell proliferation, movement and cell death. MAPKs are ubiquitous (Jonak et al., 1999), and their sequences are very conservative, with serine/threonine residues in the active core (Kyriakis \& Avruch, 2001). Several authors have shown that all plants possess MAPK homologs, which play a critical role in the cell signaling network (for a review, see Sinha et al. 2011). Despite the fact that signal transduction in algae has only recently become a research focus, different studies with microalgae (Jiménez et al., 2004, Jiménez et al., 2007, García- Gómez et al., 2012, Gasulla et al., 2016) have demonstrated that p38, JNK and ERK components are present in algae, and that they have a crucial role in acclimation to stress and in cell division.

Already in 1931, Baas-Becking proved that D. viridis presented a great ability to 402 survive in high salinity conditions. Accordingly, Borowitzka et al. (1977), Brown \& 403 Borowitzka (1979), and Jiménez \& Niell (1991) showed that D. viridis grows optimally 404 in $5.8-11.6 \%(\mathrm{w} / \mathrm{v}) \mathrm{NaCl}(1-2 \mathrm{M} \mathrm{NaCl})$, and tolerates up to $23.2 \%(4 \mathrm{M} \mathrm{NaCl})$. At lower 405 concentrations (e.g. $0.5 \mathrm{M} \mathrm{NaCl}$ ), D. viridis was unable to grow (Jiménez \& Niell, 1991). Jiménez \& Niell (2003) also reported that after a sudden increase of the salinity 
of the medium, cell carbon and nitrogen content of $D$. viridis rapidly increased, and a new stationary state was reached in a period of time that ranged between 8 and $24 \mathrm{~h}$. According to Berner et al. (1989), $24 \mathrm{~h}$ is also the time needed for a complete rearrangement of the thylakoid membranes following a light intensity transition in $D$. tertiolecta. In addition, Jiménez \& Niell (2003) concluded that different kind of stress induces similar responses in Dunaliella. Among others, there was a significant reduction of the growth rate and of the package of the pigments, and an increase of the cell volume and of the $\mathrm{C} / \mathrm{N}$ ratio.

In the present work it is demonstrated that MAPKs have a crucial role in the response of $D$. viridis to environmental stress, and that acclimation to the new conditions occurs through phosphorylation of both p38-like and JNK-like MAPKs. The estimated time for acclimation (measured as recovery of the photosynthetic efficiency) to the new conditions ranged between 8-24 h. The inhibition of either p38 or JNK phosphorylation in $D$. viridis highly impaired acclimation under stress conditions, eventually leading to cell death, in agreement with previous reports (Jiménez et al., 2004). A decrease in the capacity to acclimate to new environmental conditions, compromising eventually cell survival in the presence of specific inhibitors of the signaling pathways, suggests the existence of signaling mechanisms in algae similar to those found in mammalian cells, and that algae survive under stress conditions by activating several cell programs, among them p38 and JNK MAPK pathways.

This study has allowed the identification of the mechanisms underlying in stress acclimatization responses in the unicellular chlorophyte $D$. viridis. It has been determined the phosphorylation/de-phosphorylation levels of JNK-like, p38-like and ERK-like proteins in D. viridis cultures at their exponential growth phase long-time acclimated to different salinities $(1 \mathrm{M}$ to $4 \mathrm{M} \mathrm{NaCl})$, with significantly lower phosphorylation levels of ERK-like proteins in the cultures exposed to the maximum $\mathrm{NaCl}$ concentration (4M), and no significant differences in the phosphorylation levels of JNK-like and p38-like proteins between cultures, independently of the salinity, which indicates that a certain level of phosphorylation is necessary to keep homeostasis of this species. It was also assessed, in the short and medium term (up to $24 \mathrm{~h}$ ), the evolution of the phosphorylation levels of JNK-like, p38-like and ERK-like proteins after the cells being challenged with hyperosmotic shock, high irradiance shock and UV radiation shock (all non-lethal treatments). In general, there was an immediate increase of 
phosphorylation levels of JNK-like and p38-like proteins after stress (that coincided

441 with a recovery of photosynthetic capacity); on the contrary, phosphorylation level of

442 ERK-like MAPKs suddenly dropped, in correlation with their role in the control of cell

443 division (Jiménez et al., 2007).

444 The use of specific inhibitors of the three MAPKs studied demonstrates a direct and strong correlation between phosphorylation of the MAPKs and response to stress. A very significant decrease of photosynthetic efficiency occurs when either JNK or p38 inhibitors were applied to the cultures prior to a non-lethal stress (as determined by the in vivo fluorescence of photosystem II), being always more drastic in the case of the JNK inhibitor. This coincides with previous results of Jiménez et al. (2004) who measured a dramatic drop of cell viability when specific inhibitors were applied. Thus, it could be determined the crucial role played by JNK in the maintenance of cell viability after an environmental stress situation, and the involvement of p38 in the acclimatization process, while ERKs appear to control the cell division process, not being directly involved in the acclimatization process in the short and medium term after stress. Both p38 and JNK are essential for acclimatization (Jiménez et al., 2004) and their basal phosphorylation allows starting the response when a situation of environmental stress occurs. Blocking the phosphorylation of either MAPK significantly impaired the capacity to respond to stress in; in parallel to a decrease of the phosphorylation of these MAPKs a rapid and very significant drop of cell viability occurs, leading, in the case of total blocking of $\mathrm{JNK}$, to cell death, even at $\mathrm{NaCl}$ concentrations, irradiance or UV levels compatible with a normal development of this species. Homeostasis of $D$. viridis is crucially dependent of the phosphorylation of $\mathrm{p} 38$ and JNK MAPKs.

ERK plays an essential role in cell division (Jiménez et al., 2007; Gasulla et al., 2016) and its phosphorylation is an indicative of this division. It is well known that cell division in Dunaliella is hampered or completely arrested in stressful growth conditions (Avron, 1992). De-phosphorylation of p42/44 ERK MAPKs in D. viridis coincides with the arrest of cell division, but does not imply loss of cell viability (Jiménez et al., 2007).

In conclusion, phosphorylation of MAPK-like proteins of the type JNK and p38 is crucial for response to environmental stress in the microalga D. viridis. Activation of both kinases occurs immediately after stress, being needed between 8 and $24 \mathrm{~h}$ for a complete acclimation to new environmental conditions. ERK proteins are not involved 
in the response to stress, and they are rapidly deactivated after stress, leading to a transient inhibition of cell division.

\section{Acknowledgements}

This work was funded by Grant CGL2015-67014-R of the Spanish Ministry of Economy and Competitiveness to C.J. M.L.P is being supported by a grant of reinstatement of PhDs ("Research Own Plan". University of Málaga. Spain).

\section{References}

Avron, M., 1992. Osmoregulation. In Avron, M. \& A. Ben-Amotz (eds) Dunaliella: Physiology, Biochemistry, and Biotechnology. CRC Press, Boca Raton: 135-164.

Baker, N.R., Oxborough, K., 2004. Chlorophyll fluorescence as a probe of photosynthetic productivity. In Chlorophyll a Fluorescence (pp. 65-82). Springer, Netherlands.

Baas-Becking, L.G.M., 1931. Salt effects on swarmers of Dunaliella viridis Teod. J. Gen. Physiol. 14, 765-779.

Ben-Amotz, A., Avron, M., 1973. The role of glycerol in the osmotic regulation of the halophilic alga Dunaliella parva. Plant Physiol. 51, 875-878.

Ben-Amotz, A., Avron, M., 1983. Accumulation of metabolites by halotolerant algae and its industrial potential. Ann. Rev. Microbiol. 37, 95-119.

Ben-Amotz, A., Avron. M., 1990. The biotechnology of cultivating the halotolerant alga Dunaliella. Tibtechnology 8, 121-126.

Bennett, B.L., Sasaki, D.T., Murray, B.W., O'Leary, E.C., Sakata, S.T., Xu, W., Leisten, J.C., Motiwala, A., Pierce, S., Satoh, Y., Bhagwat, S.S., Manning, A.M., Anderson, D.W., 2001. SP600125, an anthrapyrazolone inhibitor of Jun Nterminal kinase. Proc. Nat. Acad. Sci. USA 98, 13681-13686.

Berner, T., Dubinsky, Z., Wyman, K., Falkowski, P.G., 1989. Photoadaptation and the 'package' effect in Dunaliella tertiolecta (Chlorophyceae). J. Phycol. 25, 70-78.

Borowitzka, L.J., Kessly, D.S., Brown, A.D., 1977. The salt relations of Dunaliella. Further observations on glycerol production and its regulation. Arch. Microbiol. $113,131-138$.

Brown, A.D., Borowitzka, L.J., 1979. Halotolerance of Dunaliella. In Lewandowsky M, Hutner SH (eds), Physiology and Biochemistry of Protozoa, Vol. I. Academic Press, New York, 139-190.

Capasso, J.M., Rivard, C.J., Berl, T., 2001. The expression of the gamma subunit of NaK-ATPase is regulated by osmolality via C-terminal Jun kinase and phosphatidylinositol 3-kinase- dependent mechanisms. Proc. Nat. Acad. Sci. USA 98, 13414-13419.

Chen, D., Toone, W.M., Mata, J., Lyne, R., Burns, G., Kivinen, K., Brazma, A., Jones, A., Bähler, J., 2003. Global transcriptional responses of fission yeast to environmental stress. Mol. Biol. Cell 14, 214-229. 
Danquah, A., de Zelicourt, A., Colcombet, J., Hirt, H., 2014. The role of ABA and MAPK signaling pathways in plant abiotic stress responses. Biotechnol. Adv. 32, 40-52.

García-Gómez, C., Parages, M.L., Jiménez, C., Palma, A., Mata, M.T., Segovia, M., 2012. Cell survival after UV radiation stress in the unicellular chlorophyte Dunaliella tertiolecta is mediated by DNA repair and MAPK phosphorylation. J. Exp. Bot. 63, 5259-5274.

Gasulla, F., Barreno, E., Parages, M.L., Cámara, J., Jiménez, C., Dörmann, P., Bartels, D., 2016. The role of Phospholipase D and MAPK signalling cascades in the adaption of lichen microalgae to desiccation: changes in membrane lipids and phosphoproteome. Plant Cell Physiol. 57, 1908-1920.

Hirt, H., 1997. Multiple roles of MAP kinases in plant signal transduction. Trends Plant Sci. 2, 11-15.

Jiménez, C., Niell, F.X., 1991. Growth of Dunaliella viridis Teodoresco: influence of salinity, temperature and nitrogen concentration, J. Appl. Phycol. 3, 319-327.

Jiménez, C., Niell, F.X., 2003. Influence of high salinity and nitrogen limitation on package effect and C/N ratio in Dunaliella viridis. Hydrobiologia 492, 201-206.

Jiménez, C., Berl, T., Rivard, C., Edelstein, C., Capasso, J.M., 2004. Phosphorylation of MAP kinase-like proteins mediate the response of the halotolerant alga Dunaliella viridis to hypertonic shocks. Biochim. Biophys. Acta 1644, 61-69.

Jiménez, C., Cossío, B.R., Rivard, C.J., Berl, T., Capasso, J.M., 2007. Cell division in the unicellular microalga Dunaliella viridis depends on phosphorylation of extracellular signal-regulated kinases (ERKs). J. Exp. Bot. 58, 1001-1011.

Jonak, C., Ligterink, W., Hirt, H., 1999. MAP kinases in plant signal transduction. Cell. Mol. Life Sci. 55, 203-213.

Kyriakis, J.M., Avruch, J., 2001. Mammalian mitogen-activated protein kinase signal transduction pathways activated by stress and inflammation. Physiol. Rev. 81, 807-869.

Ligterink, W., 2000. MAP kinases in plant signal transduction: how many, and what for? Res. Probl. Cell Diff. 27, 11-27.

Lurie, S., Klein, J.D., Fallik, E., 1994. Cross protection of one stress by another: strategies in postharvest fruit storage. In Biochemical and Cellular Mechanisms of Stress Tolerance in Plants (pp. 201-212). Springer, Berlin, Heidelberg.

Parages, M.L., Capasso, J.M., Meco, V., Jiménez, C., 2012. A novel method for phosphoprotein extraction from macroalgae. Bot. Mar. 55, 261-267.

Parages, M.L., Heinrich, S., Wiencke, C., Jiménez, C., 2013. Rapid phosphorylation of MAP kinase-like proteins in two species of Arctic kelps in response to temperature and UV radiation stress. Env. Exp. Bot. 91, 30-37.

Parages, M.L., Capasso, J.M., Niell, F.X., Jiménez, C., 2014. Responses of cyclic phosphorylation of MAPK-like proteins in intertidal macroalgae after environmental stress. J. Plant Physiol. 171, 276-284.

Schreiber, U., Schliwa, U., Bilger, W., 1986. Continuous recording of photochemical and non-photochemical chlorophyll fluorescence quenching with a new type of modulation fluorometer. Photosynth. Res. 10, 51-62. 
Sinha, A.K., Jaggi, M., Raghuram, B., Tuteja, N., 2011. Mitogen-activated protein kinase signaling in plants under abiotic stress. Plant Signal Behav. 6, 196-203.

Tena, G., Renaudin, J.P., 1998. Cytosolic acidification but not auxin at physiological concentration is an activator of MAP kinases in tobacco cells. Plant J. 16, 173182.

Widmann, C., Gibson, S., Jarpe, M.B., Johnson, G.L., 1999. Mitogen-activated protein kinase: conservation of a three-kinase module from yeast to human Physiol. Rev. $79,143-180$.

Yanagawa, Y., Yoda, H., Osaki, K., Amano, Y., Aono, M., Seo, S., Kuchitsu, K., Mitsuhara, I., 2016. Mitogen-activated protein kinase 4-like carrying an MEY motif instead of a TXY motif is involved in ozone tolerance and regulation of stomatal closure in tobacco. J. Exp. Bot. 67, 3471-3479. 


\section{Figure captions}

Fig. 1. Growth of $D$. viridis in function of the salinity (1 to $4 \mathrm{M} \mathrm{NaCl}$ ). Data are the mean of three replicates \pm standard deviation.

Fig. 2. Spectral irradiance emitted by the LED Explosion Proof Lamp (a), for the high irradiance experiments, and by the UV lamps (b), for the UVR experiments.

Fig. 3. a) $\mathrm{F}_{\mathrm{V}} / \mathrm{Fm}_{\mathrm{m}}$ values of long-term acclimated $D$. viridis cultures during the exponential phase of growth at increasing salinities. Cultures at $2 \mathrm{M}, 3 \mathrm{M}$ and $4 \mathrm{M} \mathrm{NaCl}$ were compared against $1 \mathrm{M} \mathrm{NaCl}$ treatment (control). A p-value $<0.05$ was considered significant and is represented with a single asterisk "**, while a $p$-value $\leq 0.001$ was considered very significant and is represented by two asterisks "***. Data are the mean of three replicates \pm standard deviation. b) Relative maximum electron transport rate $\left(\mathrm{rETR}_{\max }\right)$ of $D$. viridis long-term acclimated to $1,2,3$ and $4 \mathrm{M} \mathrm{NaCl}$ salinity in function of increasing irradiance. No significant differences between treatments were found.

Fig. 4. Band intensity (in relative units) of the three MAPK-like proteins (ERK, JNK and p38) during exponential growth at increasing salinity $(1-4 \mathrm{M} \mathrm{NaCl})$ of long-term acclimated cultures, with examples of the bands obtained by means of immunedetection with specific antibodies of the phosphorylated forms of the MAPKs. Data are the mean of three replicates \pm standard deviation. A p-value $<0.05$ was considered significantly different than the $1 \mathrm{M} \mathrm{NaCl}$ control, and is represented with a single asterisk "**, while a p-value $\leq 0.001$ was considered very significant and is represented by two asterisks "***".

Fig. 5. Evolution of the maximum quantum yield of $D$. viridis after hypersaline shock (from 1 to $2.5 \mathrm{M} \mathrm{NaCl}$ ) in the presence or absence of the specific inhibitors of the ERK, JNK and p38 cascades. Data presented correspond to time 0 before stress $(0, \mathrm{BS})$, time 0 after $2 \mathrm{~h}$ of incubation with designated inhibitor and before the detailed stress $(0, \mathrm{I})$, time 0 after stress $(0, \mathrm{AS})$, and $0.5,1,2,4,8,24$ hours after stress. Data are the mean of five replicates \pm standard deviation. A p-value $<0.05$ was considered significantly different than the time 0 before stress $(0, \mathrm{BS})$ and is represented with a single asterisk "*", while a $\mathrm{p}$-value $\leq 0.001$ was considered very significant and is represented by two asterisks “***.

Fig. 6. Time course (24 h) of the phosphorylation level of ERK-like (a), JNK-like (b) and p38-like (c) proteins after hypersaline stress, both in control cells (stress without inhibitor) and in the cells stressed after being incubated for $2 \mathrm{~h}$ with the inhibitors of the corresponding phosphorylation cascade. Relative band intensity values are shown, with examples of the bands obtained. Samples labelled 0h-BS correspond in the controls to the moment previous to the stress situation, while in the inhibition experiments they refer to the moment previous to the stress situation but 2 hours after incubation with the corresponding inhibitor. Samples labelled as 0h-AS correspond in both cases to the first moments (less than $1 \mathrm{~min}$ ) after the shock was applied. Data are the mean of three replicates \pm standard deviation. A p-value $<0.05$ was considered significantly different than the time 0 before stress (0h-BS) and is represented with a single asterisk "*", while a $p$-value $\leq 0.001$ was considered very significant and is represented with two asterisks “**”. Open symbols - treatments with specific inhibitors; closed symbols - control treatments. 
Fig. 7. Evolution of the maximum quantum yield of $D$. viridis after high irradiance shock $\left(3000 \mu \mathrm{mol} \mathrm{m} \mathrm{m}^{-2} \mathrm{~s}^{-1}\right.$ for 35 minutes) in the presence or absence of the specific inhibitors of the ERK, JNK and p38 cascade. Details of the data points as in Figure 5.

Fig. 8. Time course (24 h) of the phosphorylation level of ERK-like (a), JNK-like (b) and p38-like (c) proteins after high irradiance stress, both in control cells (stress without inhibitor) and in the cells stressed after being incubated for $2 \mathrm{~h}$ with the inhibitors of the corresponding phosphorylation cascade. Relative band intensity values are shown, with examples of the bands obtained. Samples labelled 0h-BS correspond in the controls to the moment previous to the stress situation, while in the inhibition experiments they refer to the moment previous to the stress situation but 2 hours after incubation with the corresponding inhibitor. Samples labelled as 0h-AS correspond in both cases to the first moments (less than $1 \mathrm{~min}$ ) after the shock was applied. Data are the mean of three replicates \pm standard deviation. A p-value $<0.05$ was considered significantly different than the time 0 before stress (0h-BS) and is represented with a single asterisk "*", while a $p$-value $\leq 0.001$ was considered very significant and is represented with two asterisks "**". Open symbols - treatments with specific inhibitors; closed symbols - control treatments.

Fig. 9. Evolution of the maximum quantum yield of $D$. viridis after non-lethal UV shock ( $480 \mathrm{~mJ} \mathrm{~cm}^{-2}$ of UV light in the range of 200-400 nm) in the presence or absence of the specific inhibitors of the ERK, JNK and p38 cascade. Details of the data points as in Figure 5.

Fig. 10. Time course (24 h) of the phosphorylation level of ERK-like (a), JNK-like (b) and p38-like (c) proteins after exposure to UVR, both in control cells (stress without inhibitor) and in the cells stressed after being incubated for $2 \mathrm{~h}$ with the inhibitors of the corresponding phosphorylation cascade. Relative band intensity values are shown, with examples of the bands obtained Samples labelled 0h-BS correspond in the controls to the moment previous to the stress situation, while in the inhibition experiments they refer to the moment previous to the stress situation but 2 hours after incubation with the corresponding inhibitor. Samples labelled as 0h-AS correspond in both cases to the first moments (less than $1 \mathrm{~min}$ ) after the shock was applied. Data are the mean of three replicates \pm standard deviation. A p-value $<0.05$ was considered significantly different than the time 0 before stress (0h-BS) and is represented with a single asterisk "*", while a $p$-value $\leq 0.001$ was considered very significant and is represented with two asterisks “**”. Open symbols - treatments with specific inhibitors; closed symbols - control treatments. 
Figure 1

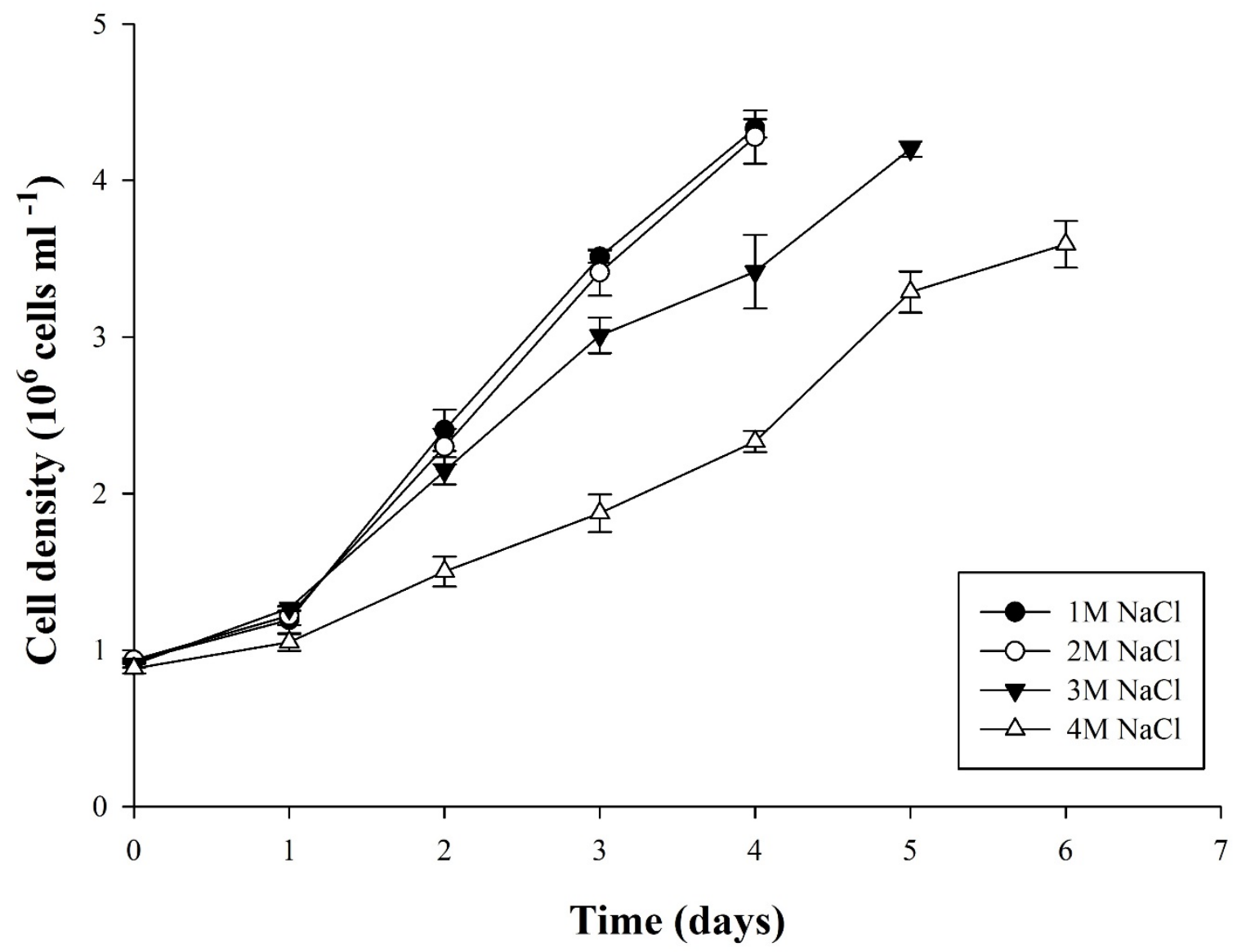


Figure 2

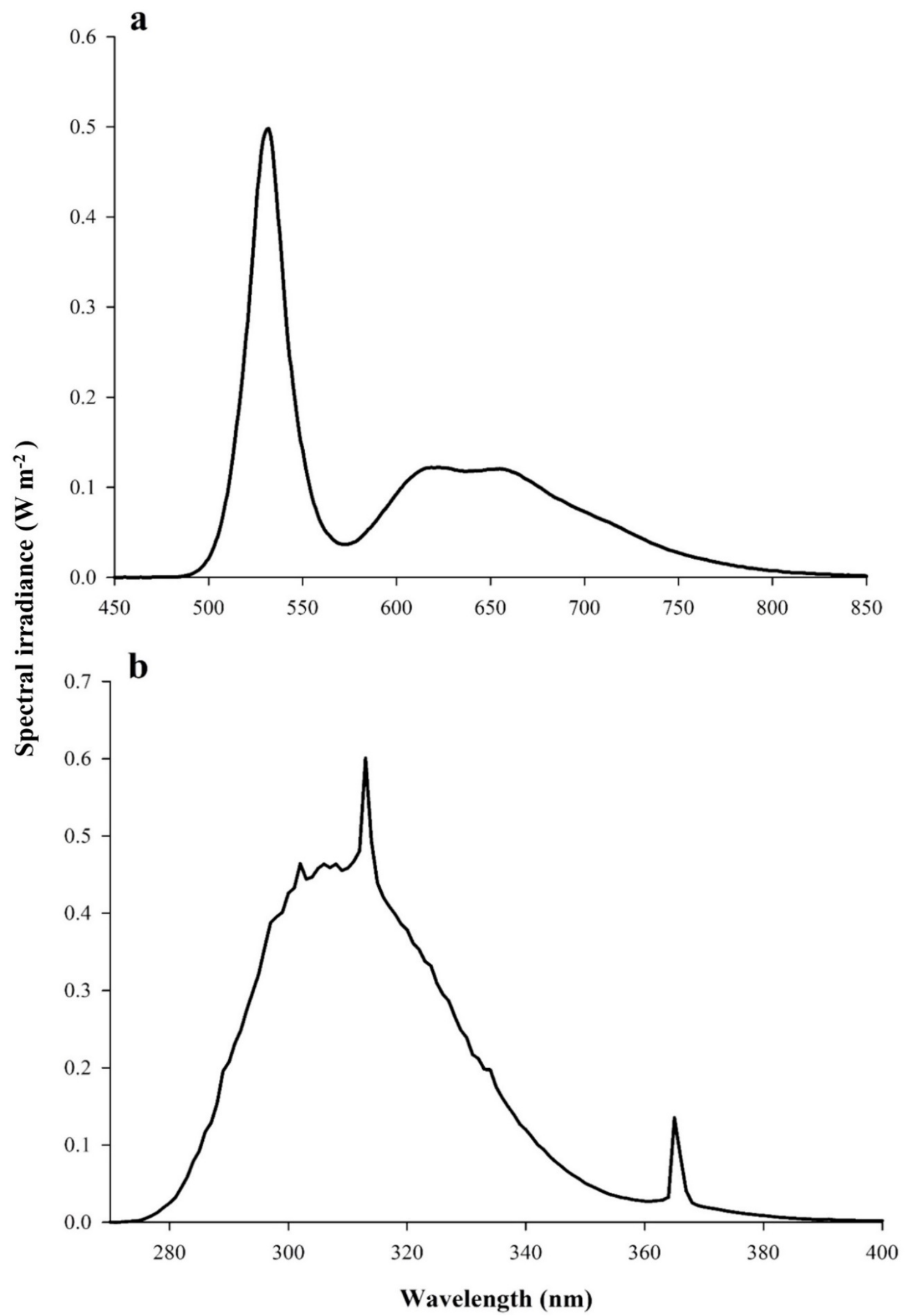


Figure 3
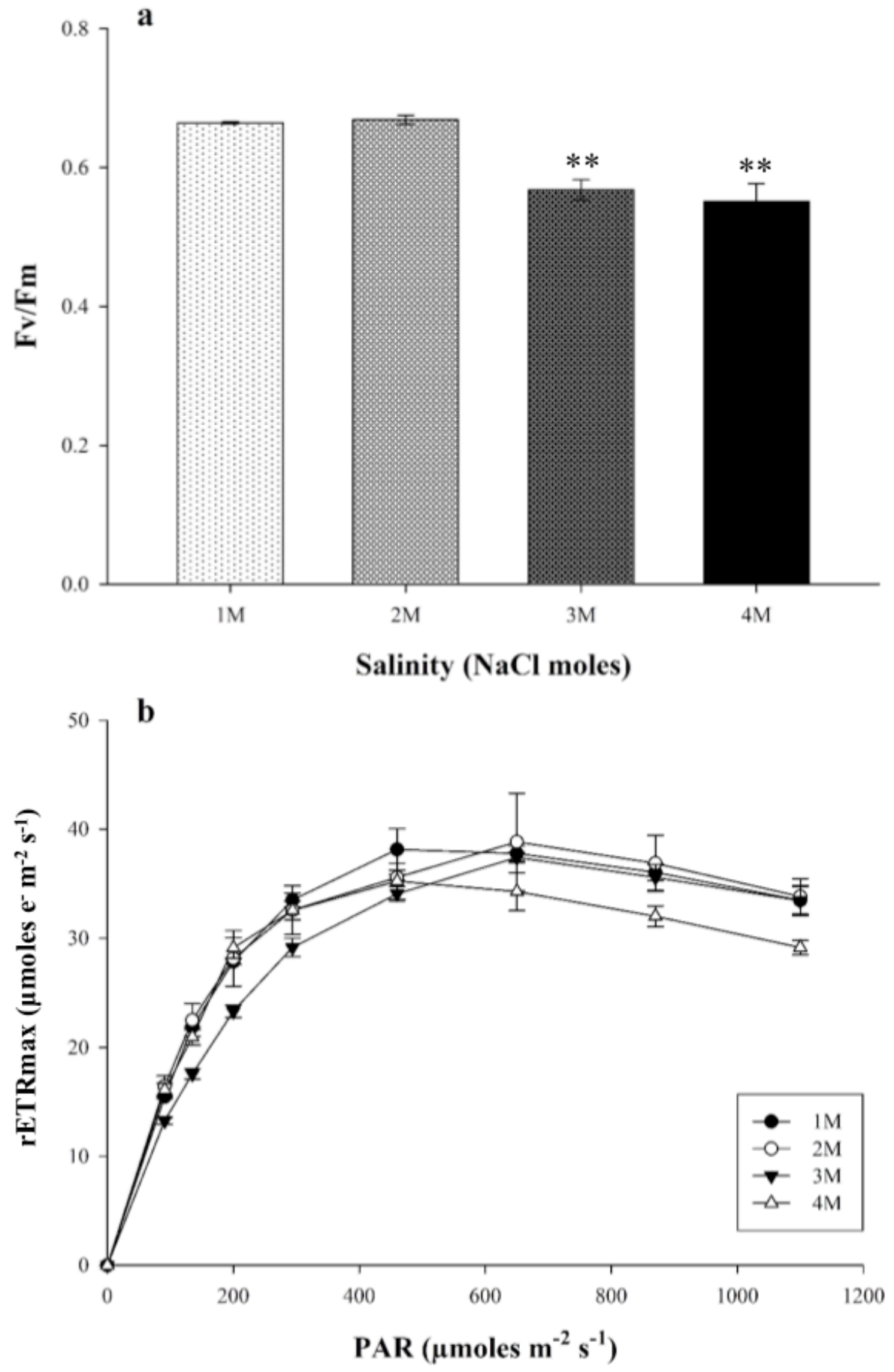
Figure 4

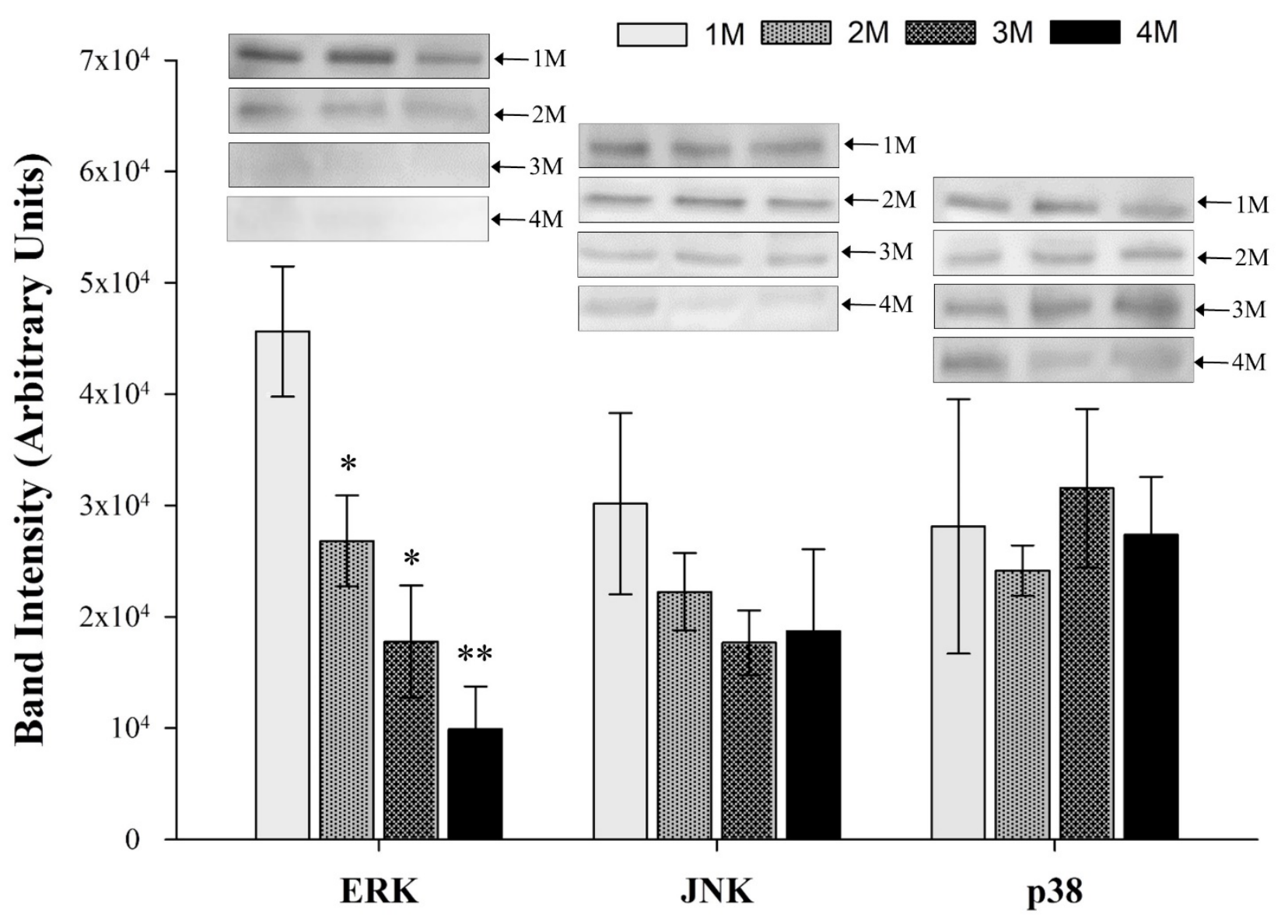


Figure 5

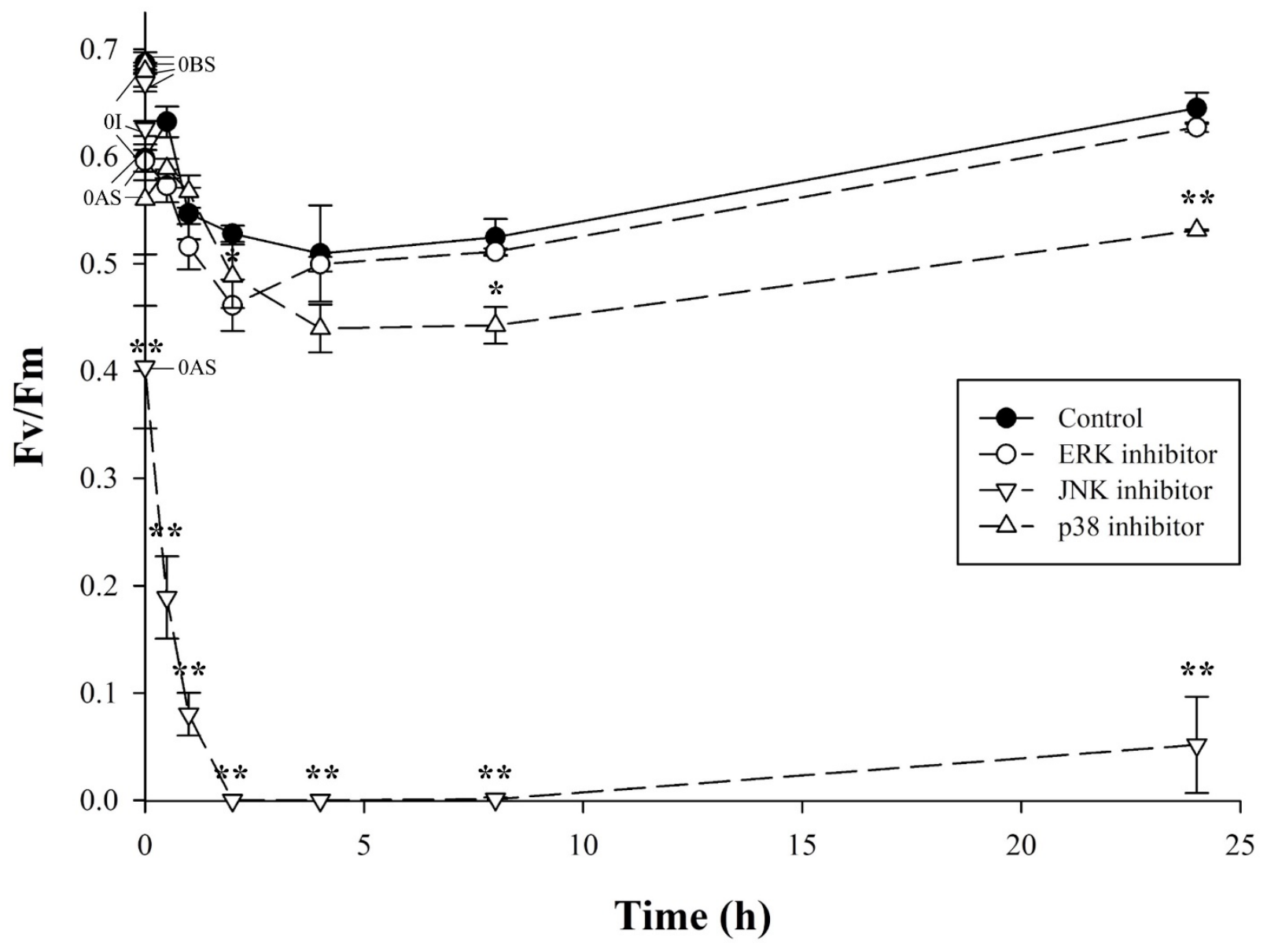


Figure 6
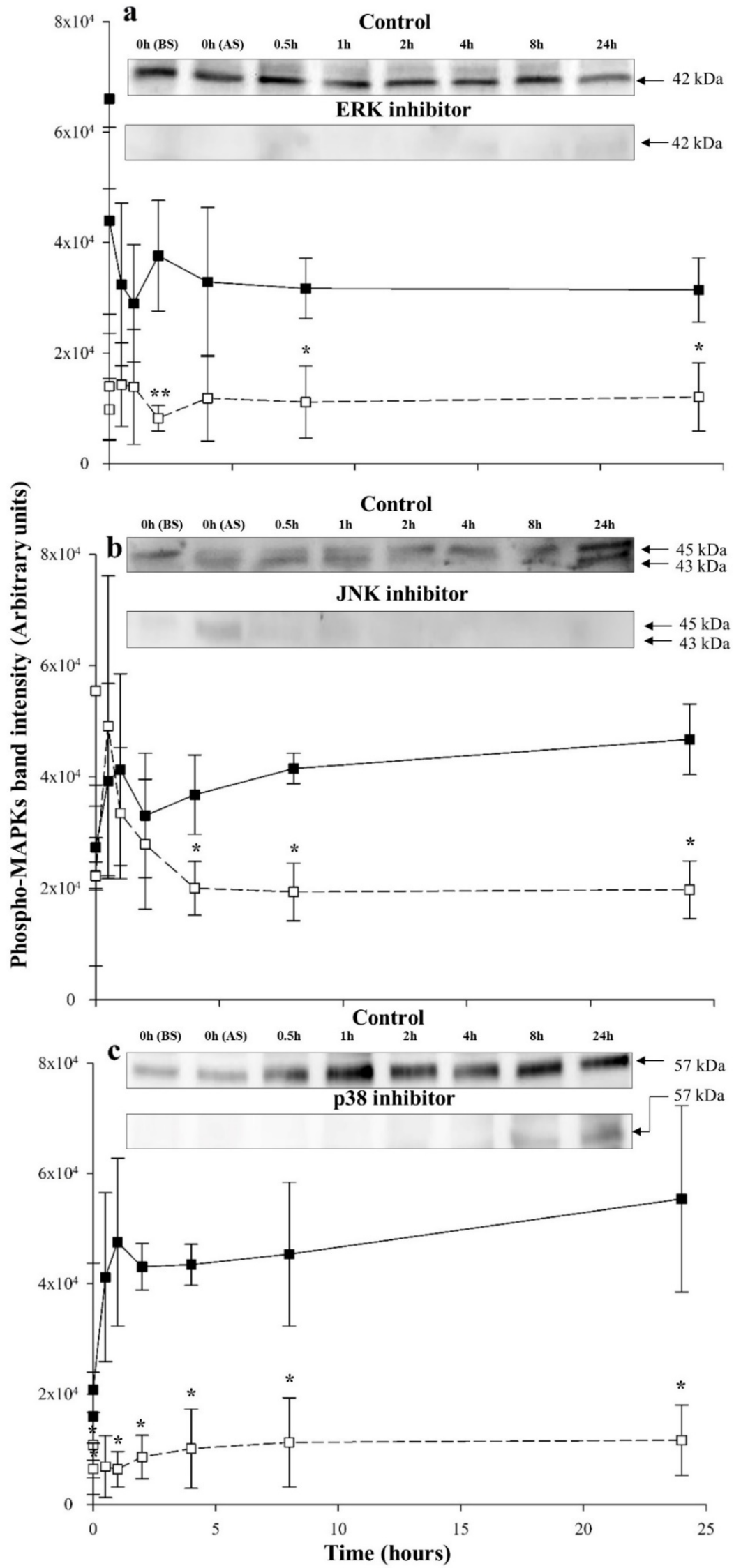
Figure 7

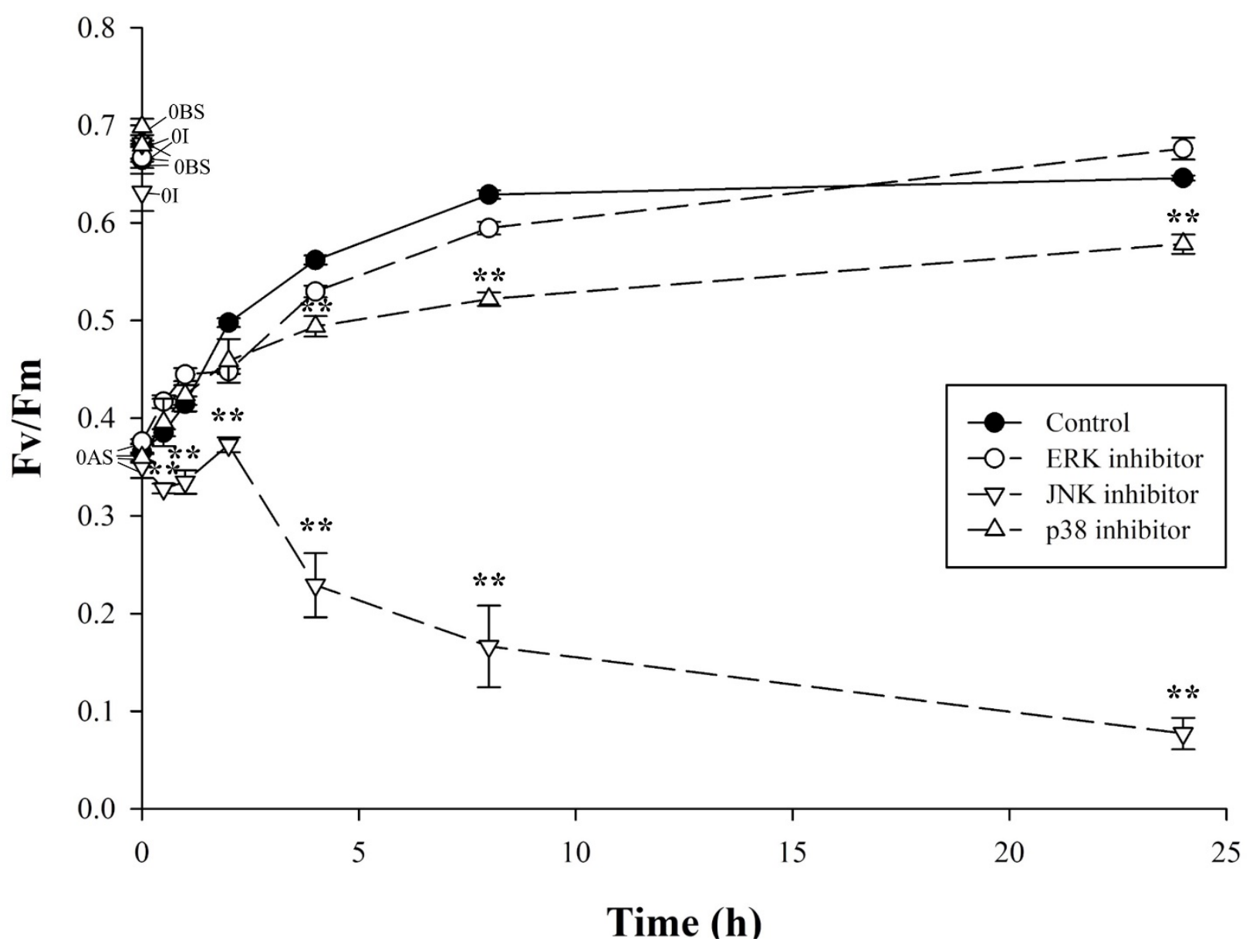


Figure 8

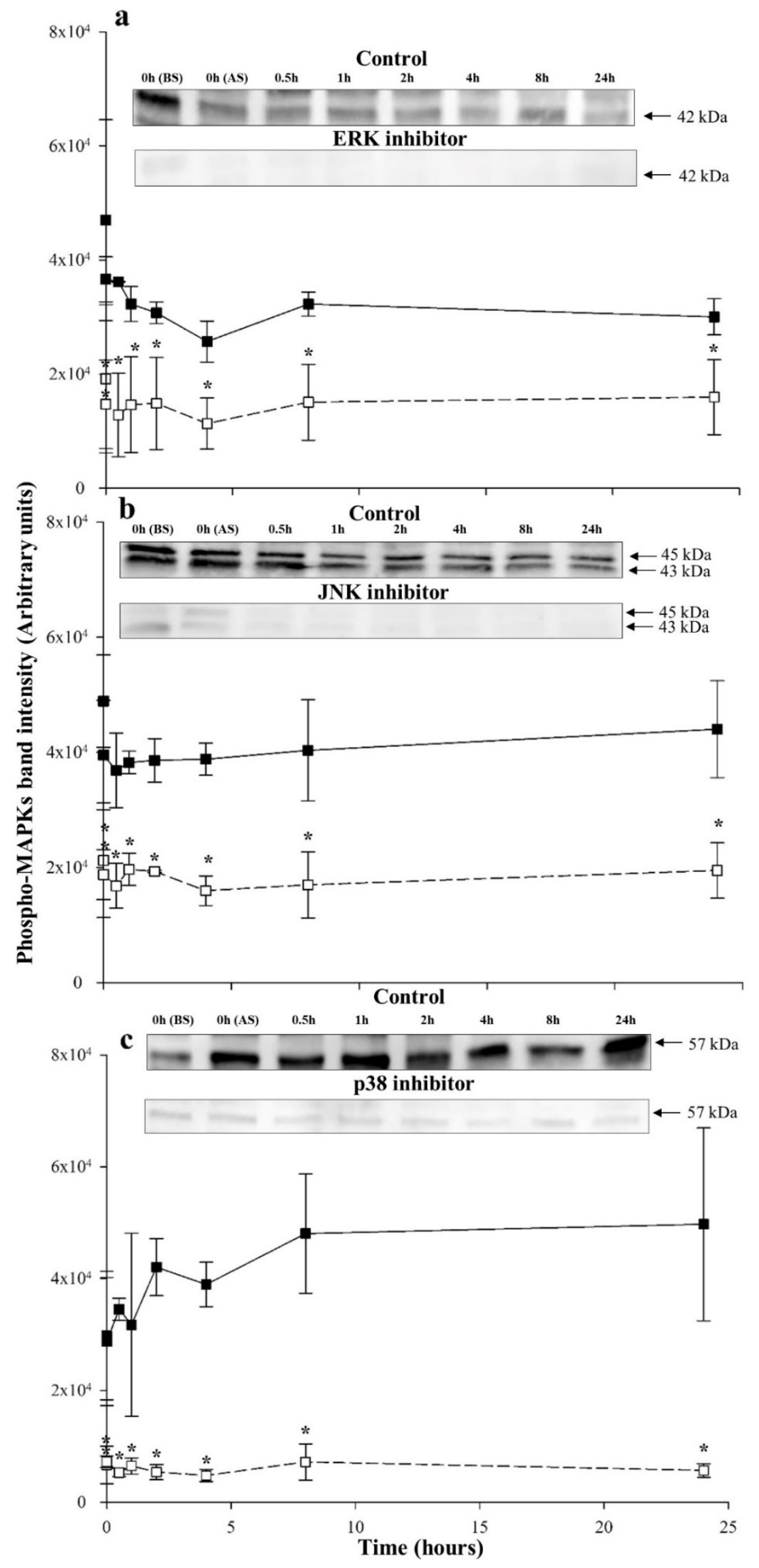


Figure 9

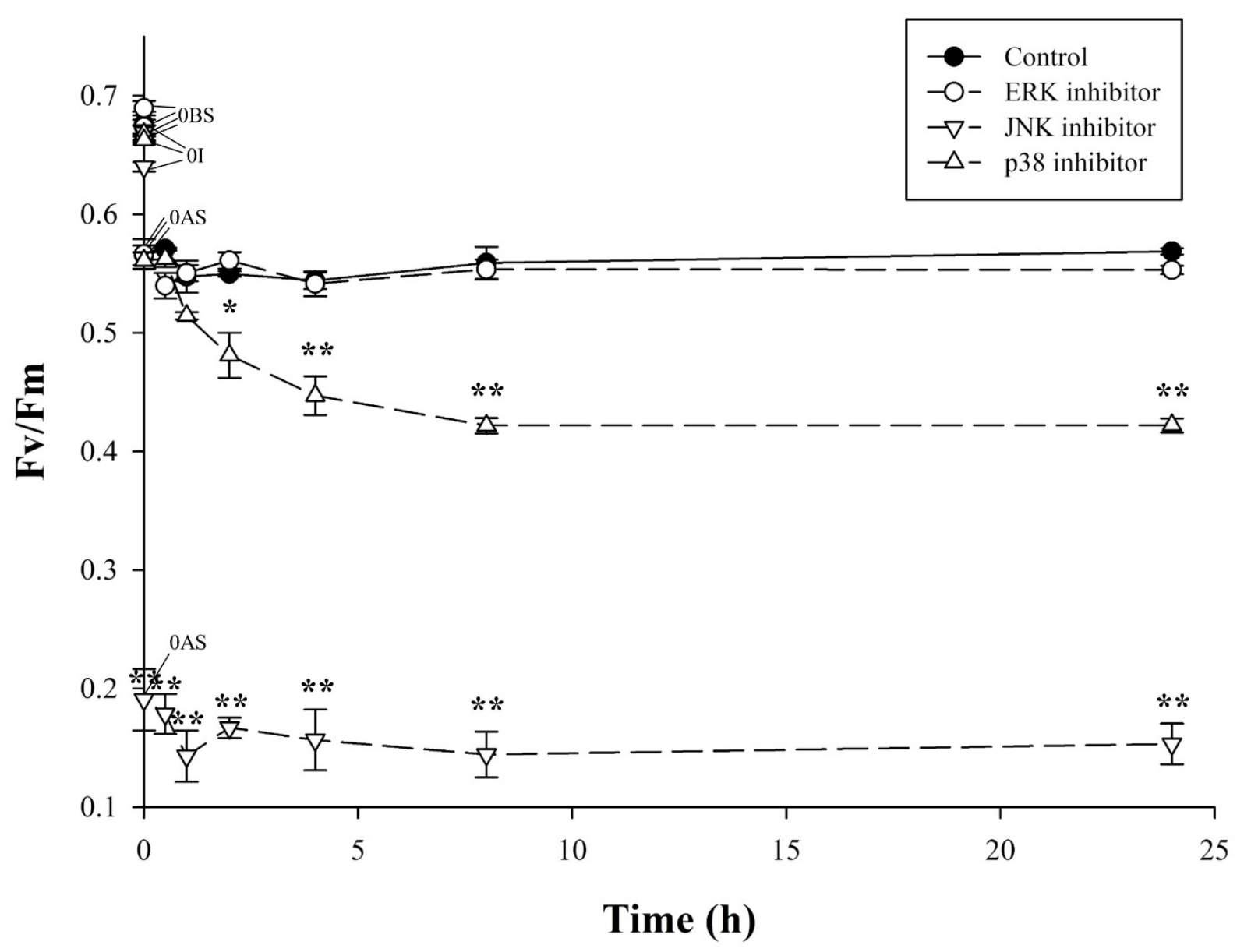


Figure 10

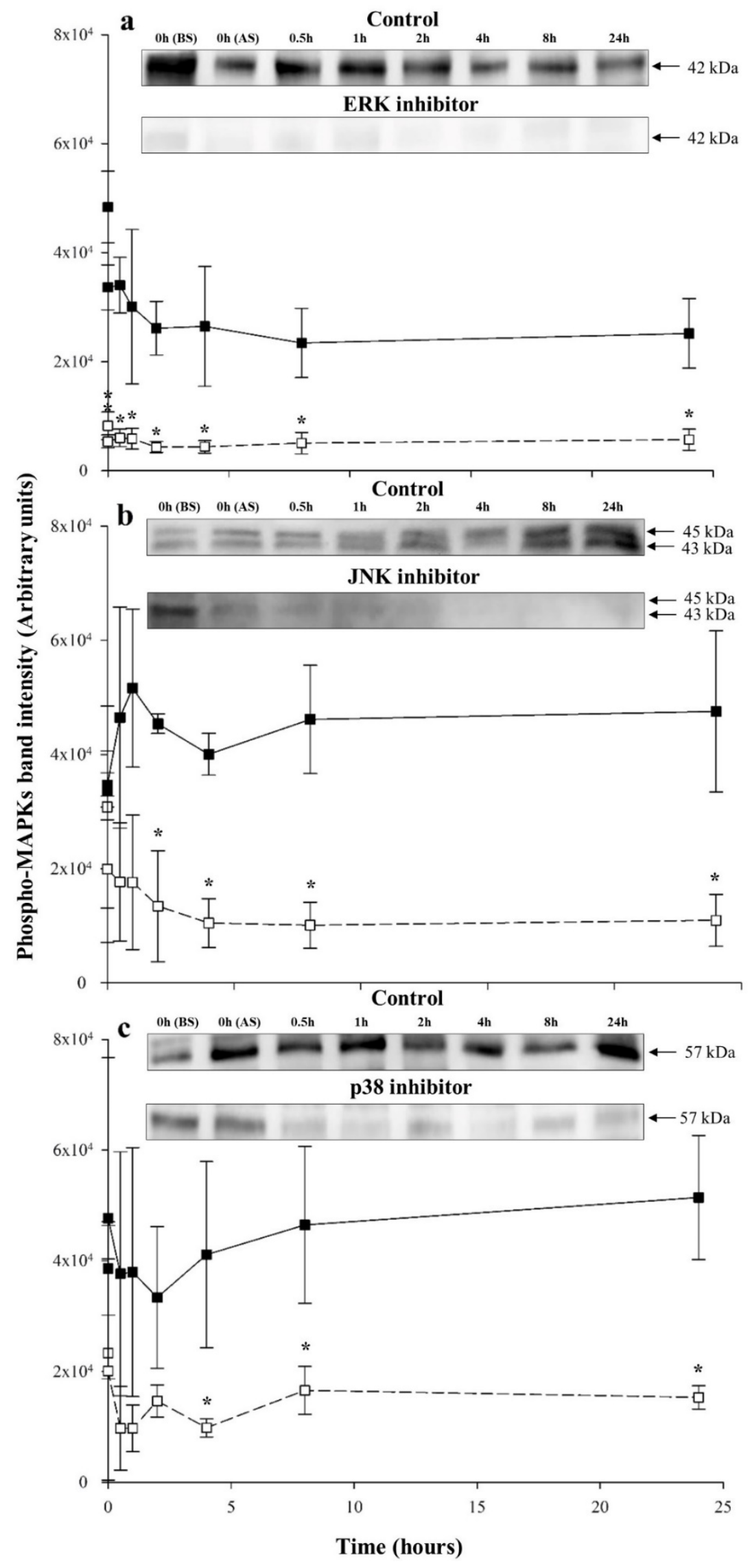

